6. Bondarenko A.O., Ponomarenko G.I. Stagnation of stolen roars during the development of genera of non-difficult problems. Naukovy Visnik NMU. 2009. № 3. P. 78-82.

7. Bondarenko A.A. On the substantiation of rational technology for the beneficiation of fine-grained materials. Mineral processing. 2008. 33 (74).

8. Bondarenko, A. A. Theoretical bases of pulp suction process in the shallow dredge underwater face. Naukovy Visnik NMU. 3, pp. 22-29. DOI: $10.29202 /$ nvngu/2018-3/4.

9. O. Medvedeva. Development and exploitation of storages of enrichment process wastes as anthropogenic deposits. Theoretical and practical solutions of mineral resources mining. London: Taylor \& Francis Group, 2015 567-573

10. Farzad Fatehi, Yevhen Semenenko, Olha Medvedieva, Larysa Tatarko and Olexander Haminich (2020). Argumentation for critical parameters and operating modes in the process of underwater mining of placers. E3S Web of Conferences, 168, 00043. https://doi.org/10.1051/ e3sconf $/ 202016800043$

DOI https://doi.org/10.30525/978-9934-588-79-2-1.30

\title{
DETERMINATION OF THE BOUNDARY SHEAR STRESS OF THE TWO-PHASE SYSTEM ON THE EXAMPLE OF A PHARMACEUTICAL MIXTURE
}

\author{
Dolomakin Y. Y. \\ Ph.D, Associate Professor, \\ Department of Machines and Apparatuses \\ for Food and Pharmaceutical Productions \\ Educational and Scientific Institute of Technical Engineering \\ by name of Academician I. S. Hulyi of the National University \\ of Food Technologies \\ Kyiv, Ukraine
}

To determine the optimal conditions for controlling the properties of dispersed structures, it is necessary to establish the mechanism and kinetics of the formation and destruction of the spatial structural grid, that is, the kinetics of the interaction of the solid phase of the mixture, water and gase- 
ous medium from the moment of appearance of the surface of separation between them until fission of the initial phases is complete.

Due to the presence of contact between the solid particles in the mixture, to overcome the structural framework they need to overcome the energy barrier, so for such a structured system is typical maximum shear stress $\tau$ (yield strength) [1].

The shear stress belongs to the integral characteristics which are taken as the structural and mechanical properties of the system as a whole such a set of interacting phases, that means a characteristic that determines the sum of elementary contact interactions between particles of the dispersed phase in the investigated volume of the dispersed system. At a load equal to the static shear stress $\left(\tau_{0}\right)$, the structure collapses and observed the shear deformation.

To get this parameter we used a methods that allows with very low (but variable) speed deformation characteristics to determine unruined structure [2].

There has been investigated the pharmaceutical suspension with different humidity (was investigated) 65,70 and $75 \%$ and different temperatures 24,28 and $35^{\circ} \mathrm{C}$. Such technological parameters are due to the fact that the suspension is formed by hydrophobic substances that are poorly wetted by water, and therefore the particles of solid phase usually accumulate in the aggregates, stick to the walls of the vessel or float to the surface.

To determine the shear stresses, was applied the method of absolute rheometry, namely a rotary rheometer with a controlled shear rate. During the work with the device to detect small values of stress was used a system of measurements $\mathrm{S} / \mathrm{S}_{1}$ (for it is constant $0.594 \mathrm{~Pa}$ ). An example of the results of this series of experiments are presented in table 1 .

Analyzing the curve built in logarithmic coordinates, we can get two parameters that describe the structural and mechanical properties of the mixture. Namely, the index of flow $n$ will be numerically equal to the tangent of the angle of inclination of the graph of direct dependence $\lg \tau-\lg \dot{\gamma}$. The second parameter that is the purpose of our research, is a segment on the axis of the ordinate, which the resulting curves are cutting off, its value will be equal to $\tau_{0}$.

This parameter acquires maximum values at minimum temperature and minimum humidity. We accept it within $2.5 \mathrm{~Pa}$. This shows that at $\tau \leq \tau_{0}$ there is no flow of the mixture and external influences cannot disrupt its strength. With the further increase of the shear stress, at $\tau>\tau_{0}$ the system is out of balance and begins to move (flow). The speed of movement in this case is insignificant, the connections between solid parts manage to recover again after their destruction. 
Table 1

Determination of shear stress at different humidity at temperature $28^{\circ} \mathrm{C}$

\begin{tabular}{|c|c|c|c|c|c|c|}
\hline \multirow{2}{*}{$\begin{array}{c}\text { Shear rate } \\
\dot{\gamma}, \mathrm{sec}^{-1}\end{array}$} & \multicolumn{3}{|c|}{$\begin{array}{c}\text { Indicator device readings } \alpha, \\
\text { scale divisions }\end{array}$} & \multicolumn{3}{c|}{ Shear stress $\tau, \mathrm{Pa}$} \\
\cline { 2 - 7 } & $65 \%$ & $70 \%$ & $75 \%$ & $65 \%$ & $70 \%$ & $75 \%$ \\
\hline 0.5 & 4.9 & 0.1 & 0.0 & 2.9302 & 0.0637 & 0.001 \\
\hline 0.9 & 5.6 & 0.5 & 0.1 & 3.3124 & 0.3185 & 0.0637 \\
\hline 1 & 6.0 & 0.9 & 0.2 & 3.5672 & 0.5096 & 0.09555 \\
\hline 1.5 & 7.2 & 1.2 & 0.3 & 4.2679 & 0.73255 & 0.1911 \\
\hline 1.8 & 7.6 & 1.6 & 0.5 & 4.5227 & 0.9555 & 0.3185 \\
\hline 2.7 & 9.5 & 2.5 & 0.9 & 5.6693 & 1.4651 & 0.5096 \\
\hline 3 & 10.3 & 2.9 & 1.0 & 6.1152 & 1.7199 & 0.5733 \\
\hline 4.5 & 12.0 & 3.4 & 1.3 & 7.1344 & 2.0384 & 0.7644 \\
\hline 5.4 & 13.7 & 4.2 & 1.5 & 8.1536 & 2.4843 & 0.8918 \\
\hline 8.1 & 17.4 & 5.6 & 2.1 & 10.3194 & 3.3124 & 1.274 \\
\hline 9 & 18.4 & 6.1 & 2.3 & 10.9564 & 3.59905 & 1.3377 \\
\hline 13.5 & 23.4 & 8.3 & 3.2 & 13.8866 & 4.9049 & 1.911 \\
\hline 16.2 & 26.4 & 9.1 & 3.5 & 15.6702 & 5.4145 & 2.1021 \\
\hline 24.3 & 33.5 & 12.9 & 5.3 & 19.8744 & 7.644 & 3.1213 \\
\hline 27 & 35.8 & 13.7 & 5.5 & 21.2758 & 8.12175 & 3.2487 \\
\hline
\end{tabular}

To obtain a specific value of the shear stress, we construct curves in double logarithmic coordinates, figure 1 and 2 .

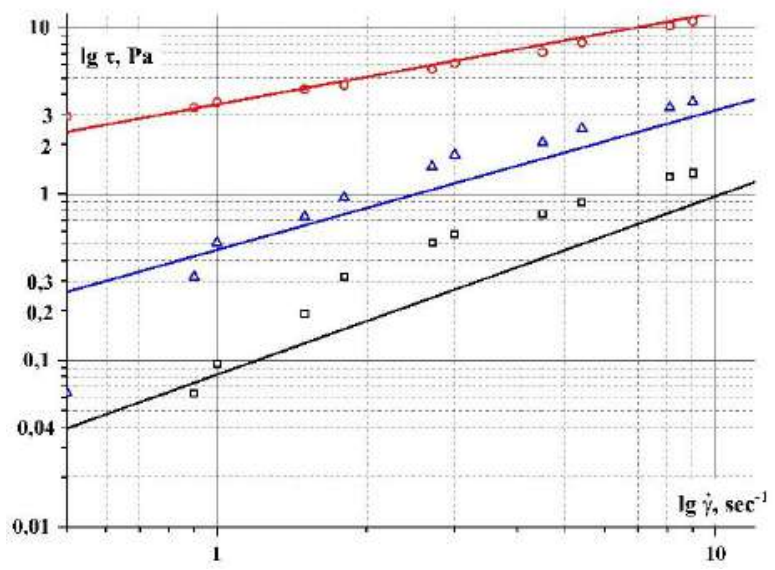

Fig. 1. Boundary shear stress for a mixture with different humidity $\left({ }^{\circ}-65 \% ; \Delta-70 \% ; \tau-75 \%\right)$ 


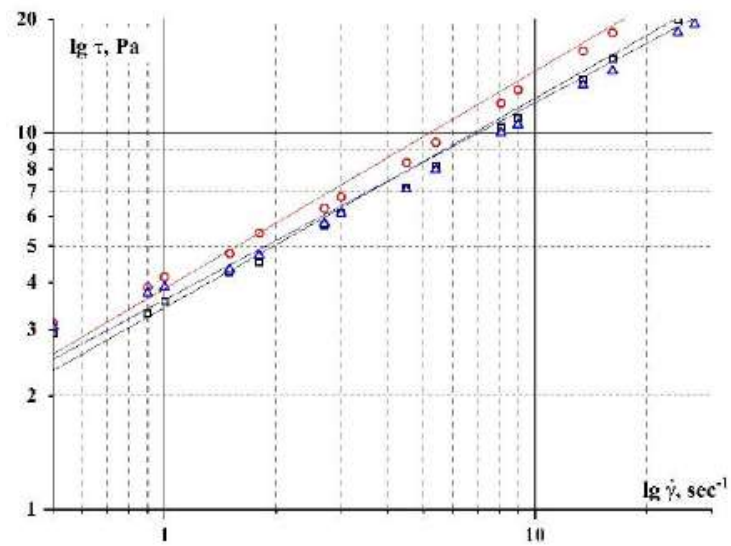

Fig. 2. Boundary shear stress for a mixture with different temperatures $\left({ }^{\circ}-24^{\circ} \mathrm{C} ; \Delta-28^{\circ} \mathrm{C} ; \tau-35^{\circ} \mathrm{C}\right)$

Thus, such a pharmaceutical mixture can be classified as a viscoplastic liquid, which, in addition to viscosity, also has plastic properties, that consist in the presence of a certain shear stress, only after which occurs the "fluidity" of the medium.

The analysis of the results allows to make conclusions that the pharmaceutical mixture with a humidity of $65 \%$ has the maximum shear stress. With increasing humidity up to $75 \%$ its value such little that it can be neglected. Theoretically, accepting $\tau_{0}=0$, the mixture can be attributed to pseudoplastic liquids. Historically, the prefix "pseudo" which is added to a group of liquids that called plastic, and this is due to the fact that yield point of such liquids equal to zero [3].

\section{References:}

1. Mastilovic, J., Popov, S., 2001. Investigation of rheological properties of liquid sourdough. In: The Third Croatian Congress of Cereal Technologists, Opatija, Croatia, 14-17 November 2001

2. Dolomakin Y.Y. Searching for the limit yield stress of liquid sourdough // Збірник наукових праць молодих учених, аспірантів та студентів ОНАХТ. - Одеса: 2016. с. 43-44

3. Лойцянский Л.Г. Механика жидкости и газа: Учеб. для вузов. 7-е изд., испр. М.: Дрофа, 2003. 840 с. 